\title{
Stress-strain state experimental researches of the lattice support pole sections for overhead power transmission line $110 \mathrm{kV}$
}

\author{
Anton Tanasoglo ${ }^{1}$, and Igor Garanzha ${ }^{2, *}$ \\ ${ }^{1}$ Donbass National Academy of Civil Engineering and Architecture, Department of Metal \\ Constructions and Structures, 2, Derzhavina str., Makeevka, Ukraine, 86123 \\ ${ }^{2}$ Moscow State University of Civil Engineering, 129337, Yaroslavskoe shosse, 26, Moscow, Russia
}

\begin{abstract}
An article compares the theoretical and experimental researches of joint work of steel tower type supports' fragments of overhead power transmission lines (OHPL) $110 \mathrm{kV}$. Attention is focused to high voltage supports operated on the Ukraine territory. Is described a spending principle of static experimental researches for flat trusses on the developed specialized experimental installation, allowing to investigate the joint work of overhead lines supports' fragments. Are presented the technique and results of the flat support model calculation in the "SCAD" software package. Are presented calculation numerical results of the experimental installation together with a testing model. Are determinated experimental values of stresses in lattice elements and also horizontal and vertical displacements of braces holding on nodes. During the displacements determining is analyzed the joint work of the lattice elements of the experimental samples, is taken into account the supporting effect of the extended braces.
\end{abstract}

\section{Structures of high voltage metal supports}

Steel supports installed on high-voltage transmission lines have wide variety solutions [1-4, $21,22]$. Supports used on high voltage transmission lines, according to the constructive implementation of the pole can be reduced to two basic designs - tower or single-pole (figure 1) and portal supports (figure 2), and by the method of pole anchoring on the foundations - to the free-standing supports (figure1) and to the support on cables (figure 3).

The main disadvantage of the supports on cables is the large area of the alienated land, and the portal supports - the number of foundations doubled with respect to single-poles and the steel overrun $[5,6]$. The number of foundations reduction is particularly useful when supports are installated in mountainous areas, river areas and in wetlands, and the decrease in the alienated land areas is important for routes passing through densely populated areas in the urban area and agricultural land. In this connection, in recent years much attention has been paid to the development of tower-type free-standing supports, assembled from individual elements on bolts [7].

\footnotetext{
*Corresponding author: garigo@mail.ru
} 


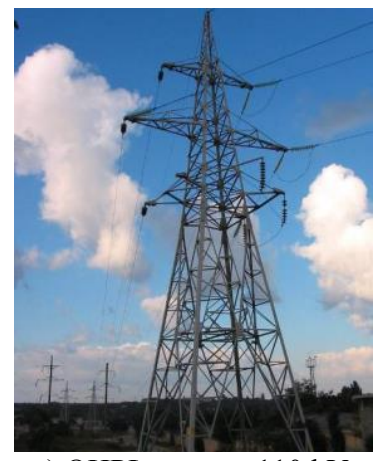

a) OHPL support $110 \mathrm{kV}$

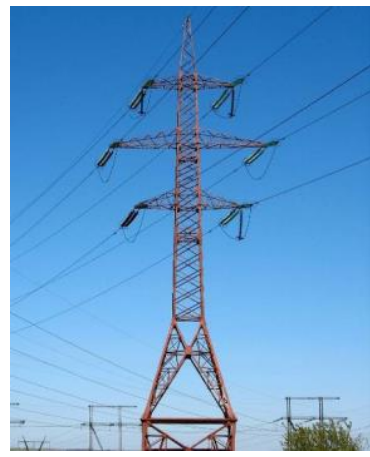

b) OHPL support $220 \mathrm{KV}$

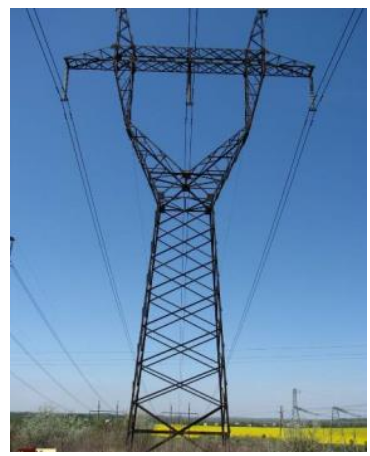

c) OHPL support $330 \mathrm{\kappa V}$

Fig. 1. General view of the OHPL tower type single-pole free-standing supports

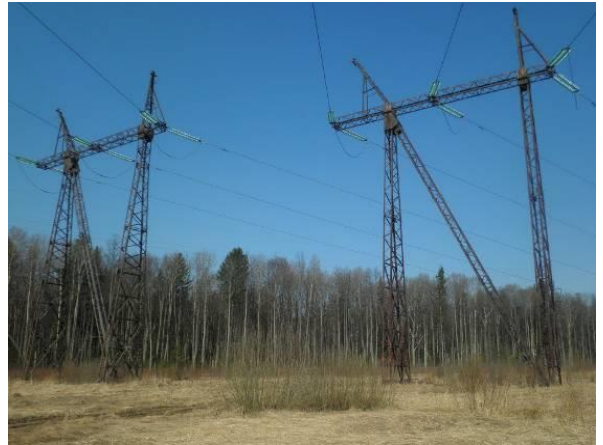

Fig. 2. General view of the OHPL portal support

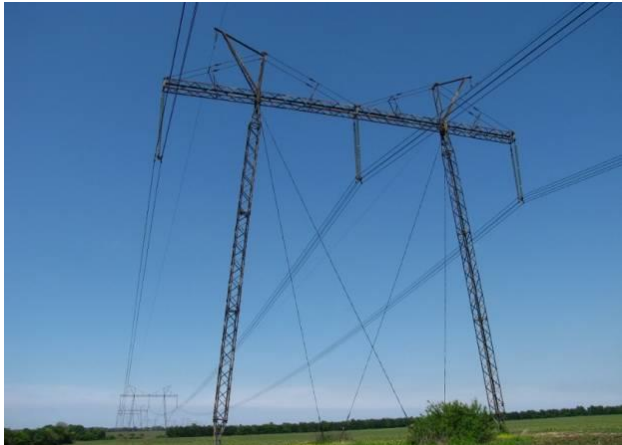

Fig. 3. General view of the OHPL cables support

\section{Setting goals and objectives of experimental researches}

One of the main elements of the electric network are overhead transmission lines, reliable work of which largely determines the uninterrupted supply of electricity to consumers. Increasing the reliability of OHPL can be achieved by researching and improving methods for calculating the strength and stability of structural support elements.

In the supports the most common used a cross-lattice with combined nodes in adjacent faces, the elements of which are made of single rolling corners connected to each other along one shelf on bolts. The nodes of braces abutment to the chords in such lattice are obtained not centered because the braces geometric axes are not aligned with the axes of forces passing through the braces [8-10]. The resulting bending moments predetermine the early development of plastic deformations [11, 12, 23-26]. The load-bearing capacity of such systems is largely determined by the error with which internal forces are counted in its individual elements [13-16]. If, in addition, take into account the imperfection of the actual structure (curvature of the rods, compliance of bolted joints and supporting fastenings), then with a high degree of static indeterminacy of the system, the correctness of the analytical solution will depend not only on the degree of accuracy of this or that calculation method, but also on the consistency of the accepted design model and full-scale structure [17-19].

The practical feasibility of such tasks requires conducting experimental studies of the power transmission line supports. And since the most massive on the Ukraine territory the metal supports of the OHPL $110 \mathrm{kV}$, then as the experimental samples were adopted the natural fragments of the support U110-2. 


\section{Spending technique of experimental researches for support fragments}

A goal of the experimental researches is to determine the stress-strain state of the support $110 \mathrm{kV}$ fragments in order to determine their actual work, as well as to carry out a comparative analysis of obtained theoretical and experimental results.

As an object of experimental research, were adopted the fragments of steel support U110-2 pole. The tested structures of flat trusses are designed in full size and made on the "Donetsk Power Transmission Tower Plant".

Tested flat sections were taken from three panels of single corners, most commonly used in the lattice of $110 \mathrm{kV}$ overhead transmission lines: the first option (figures 4 and 8) braces cross-section L63 5 , chord - L125x8, the second option (figures 5 and 9) - braces cross-section L45x4, chord- L125x8.

The structures of flat trusses are designed in accordance with the requirements of $[2,16$, 20]. The chords sections are selected so that it is possible to constructively be able to attach the braces to the chords with two bolts M20 for the first option and two bolts M16 for the second option.

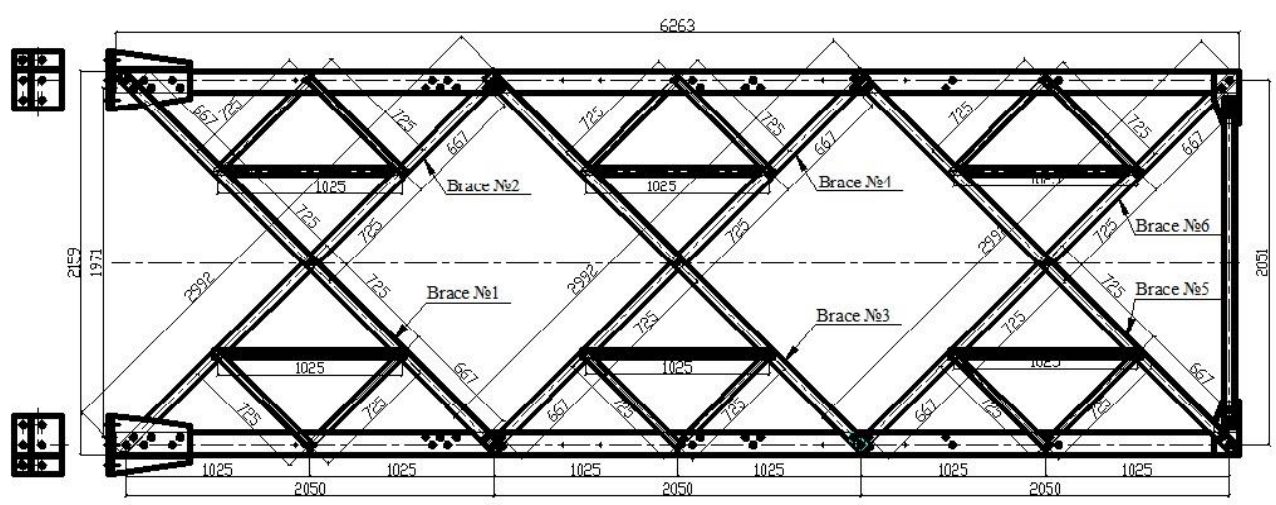

Fig. 4. Mounting scheme of the testing flat farm (braces from corners L63 x5)

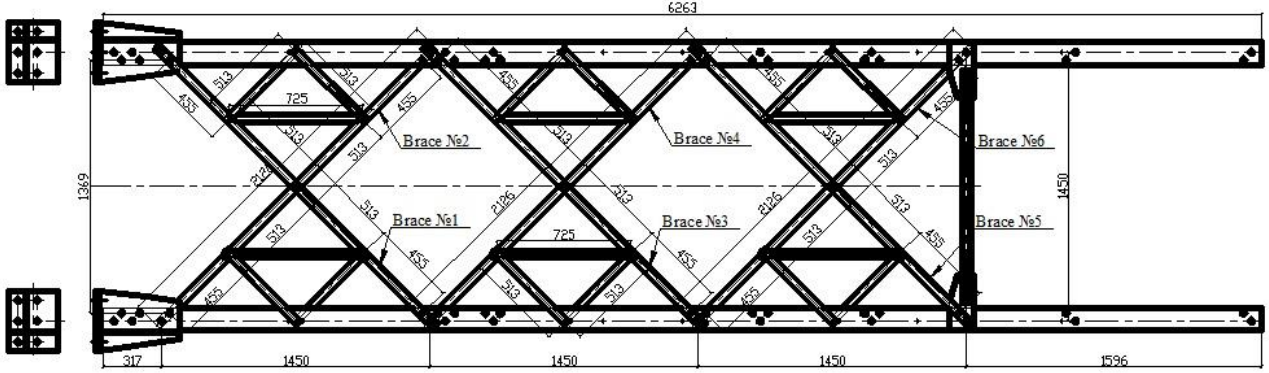

Fig. 5. Mounting scheme of the testing flat farm (braces from corners L45 $\times 4$ )

For carrying out the experimental tests of the support U110-2 fragments was designed the special experimental installation (figure 6). The testing flat truss 1 is installed on the supporting power pedestal 2. Fixing the truss is carried out by anchor bolts M20 through the tower base to the support I-beam 3, which is welded to the pedestal. In addition the struts 4 are installed for ensuring the stability of the I-beam from the plane. The hydraulic jack 6 is mounted on the support structure 5, bolted to the pedestal. For loading the experimental support fragments with a testing load is used the manual oil station 7 . 


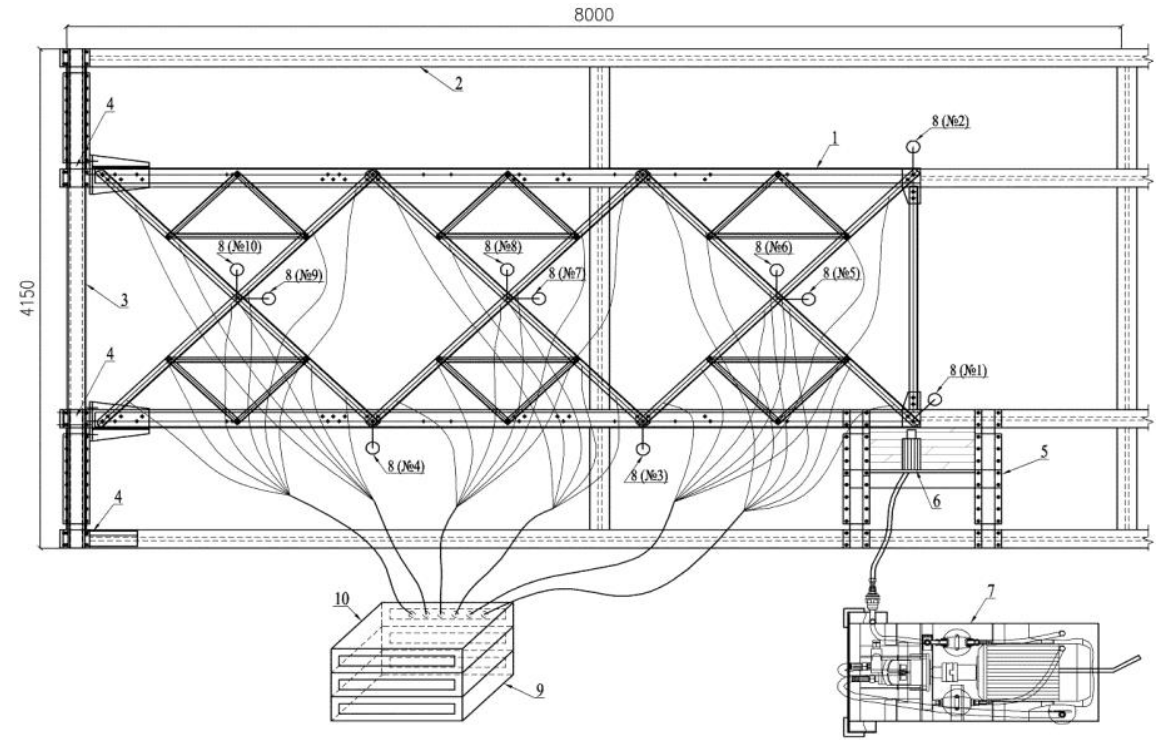

Fig. 6. The experimental installation design: 1 - support's testing fragment; 2 - metal power pedestal; 3 - support I-beam; 4 - struts; 5 - jack support structure; 6 - hydraulic jack DG-10; 7 - manual oil station with pressure gauge; 8 - Maximov's and Aistov's flexometers; 9 - tensometric system SIIT-3; 10 - switch block.

On the testing flat trusses are installed Maximov's and Aistov's flexometers 8 (figures 6 and 9) in the amount of 10 pcs. for measuring the nods displacements of abutment the braces to the chord and the nods of braces intersection with each other in the plane of load application and from the plane.

Figure 7 shows a three-dimensional design model of the experimental installation with a test sample for numerical and experimental researches.

On the basis of the DonNACEA test center, are carried out the experimental researches of fragments of the steel tower-type support U110-2.

The tests of flat trusses were carried out in four stages: with a double-bolts and singlebolt fastening of the braces to the chord; with the subdiagonal lattice and without it.

During the experimental researches were solved the following problems: the identification of the actual longitudinal forces $\mathrm{N}$ and the stresses $\mathrm{G}$ in the braces elements; determination of horizontal and vertical displacements of the braces fastening points to the truss chord and to each other; revealing the actual load-bearing capacity of the entire structure and its assemblies with single-bolt and double-bolts fastening of the braces to the chord.

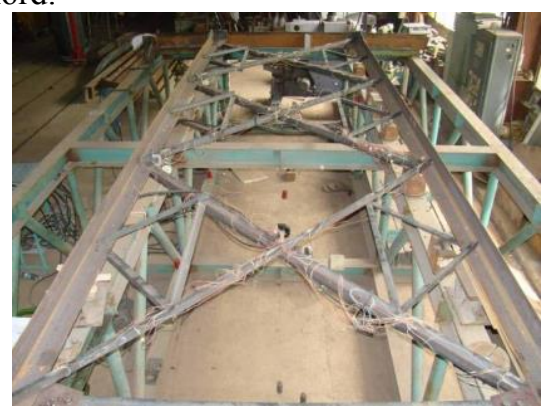

Fig. 7. Experimental truss general view (lattice L63x5)

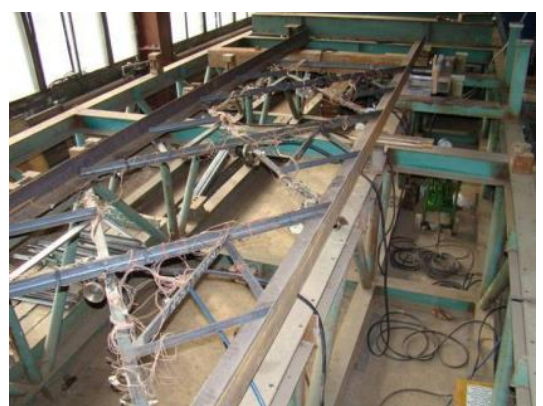

Fig. 8. Experimental truss general view (lattice L45x4)

Load on the structure was applied by the hydraulic jack DG-10 (figure 10) step by step in three stages with the intensity of $1000 \mathrm{~kg}$. After each loading phase was maintained a 
pause of 15-20 minutes up to the complete stabilization of the structural deformations, then reports were taken on all the devices and then followed the next stage of loading. Unloading was carried out in similar stages. The load was applied so as to exclude any dynamic effect. The maximum nodal load was $3000 \mathrm{~kg}$.

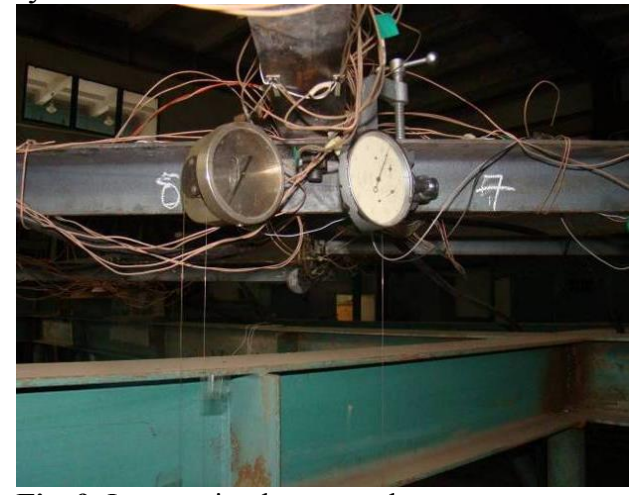

Fig. 9. Intersection braces node

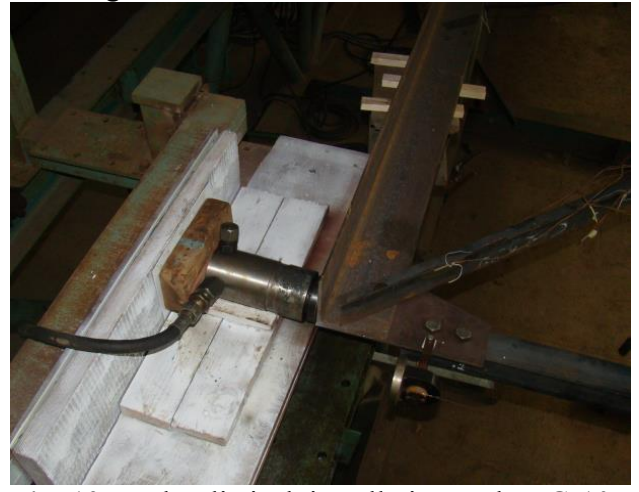

Fig. 10. Hydraulic jack installation node DG-10

For measuring the relative deformations during the tests, used wire loop resistance strain gauges on a paper basis with a base of $20 \mathrm{~mm}$ (PKB mark with electrical resistance $\mathrm{R}=200 \mathrm{Ohm}$ ). Strain gauges are installed near the nodes by six sections in each brace (figures 11 and 12). As the recording equipment was used the special strain gauge system SIIT-3.

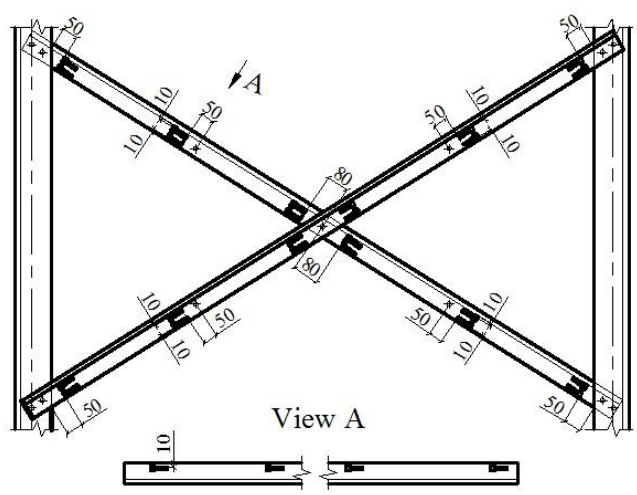

Fig. 11. The circuit arrangement of strain gauges

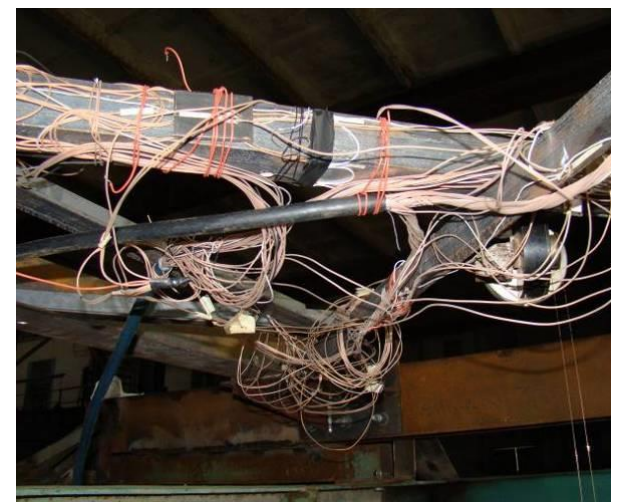

Fig. 12. Braces with resistance strain gauges

As a result of experimental researches stresses and longitudinal forces in the braces were obtained (table 1 and 2) and are shown comparative graphs of the theoretical and experimental values for nodes displacements (figures $13-16$ ).

Table 1. Longitudinal forces $N(t)$ and stresses $\sigma(\mathrm{MPa})$ in flat truss elements (lattice L63x5).

\begin{tabular}{|c|c|c|c|c|c|}
\hline \multirow{2}{*}{ Brace № } & \multicolumn{2}{|c|}{ Theoretical values } & \multicolumn{2}{c|}{ Experimental values* } & \multirow{2}{*}{ Error, \% } \\
\cline { 2 - 5 } & $\mathbf{N}_{\text {num., } \mathbf{~ k g}}$ & $\boldsymbol{\sigma}_{\text {num., }}, \mathbf{M P a}$ & $\mathbf{N}_{\text {exp. }}, \mathbf{k g}$ & $\boldsymbol{\sigma}_{\text {exp. }}, \mathbf{M P a}$ & \\
\hline 1 brace & -2276.5 & 37.14 & $-1959 /-2091.3$ & $31.96 / 34.12$ & $13.93 / 8.14$ \\
\hline 2 brace & 2073.6 & 33.83 & $1643.5 / 1292.8$ & $26.81 / 21.09$ & $20.74 / 37.65$ \\
\hline 3 brace & -2075.4 & 33.86 & $-1682 /-1626.7$ & $27.44 / 26.54$ & $18.94 / 21.62$ \\
\hline 4 brace & 2274.7 & 37.11 & $2307.4 / 2627.0$ & $37.64 / 42.86$ & $1.42 / 13.41$ \\
\hline 5 brace & -2276.0 & 37.13 & $-2269 /-2747.4$ & $37.03 / 44.82$ & $0.27 / 17.16$ \\
\hline 6 brace & 2074.2 & 33.84 & $1753.5 / 1384.7$ & $28.61 / 22.59$ & $15.46 / 33.24$ \\
\hline
\end{tabular}


Table 2. Longitudinal forces $N(t)$ and stresses $\sigma(\mathrm{MPa})$ in flat truss elements (lattice L45x4).

\begin{tabular}{|c|c|c|c|c|c|}
\hline \multirow{2}{*}{ Brace № } & \multicolumn{2}{|c|}{ Theoretical values } & \multicolumn{2}{c|}{ Experimental values* } & \multirow{2}{*}{ Error, \% } \\
\cline { 2 - 5 } & $\mathbf{N}_{\text {num. }} \mathbf{~ k g}$ & $\boldsymbol{\sigma}_{\text {num., }}, \mathbf{M P a}$ & $\mathbf{N}_{\text {exp., } \mathbf{~ k g}}$ & $\boldsymbol{\sigma}_{\text {exp. }}, \mathbf{M P a}$ & \\
\hline 1 brace & -2064.2 & 59.32 & $-2003 /-2667.6$ & $57.57 / 76.65$ & $2.94 / 22.62$ \\
\hline 2 brace & 1946.7 & 55.94 & $1848.4 / 1788.9$ & $53.12 / 51.41$ & $5.05 / 8.11$ \\
\hline 3 brace & -2031.9 & 58.39 & $-1829 /-1583.9$ & $52.57 / 45.52$ & $9.97 / 22.05$ \\
\hline 4 brace & 2257.3 & 36.82 & $2134.2 / 2564.0$ & $34.82 / 41.83$ & $5.45 / 11.96$ \\
\hline 5 brace & -2260.7 & 64.96 & $-2115.1 /-2469$ & $60.78 / 70.98$ & $6.44 / 8.47$ \\
\hline 6 brace & 1963.7 & 56.43 & $1525.2 / 1434.8$ & $43.83 / 41.23$ & $22.33 / 26.93$ \\
\hline
\end{tabular}

$*$ in the numerator are given the values for a double-bolts braces fastening to the chord with the installation of a subdiagonal lattice, in the denominator - for single-bolt braces fastening without the subdiagonal lattice.

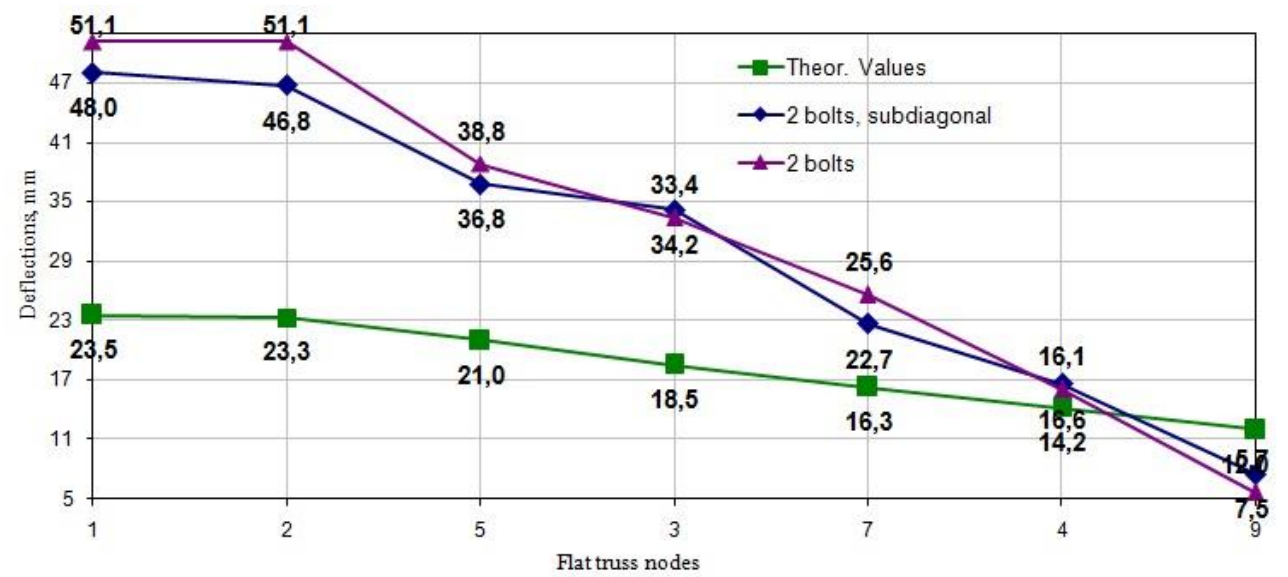

Fig. 13. Nodes displacements with two-bolts braces fastening (lattice L63 5 )

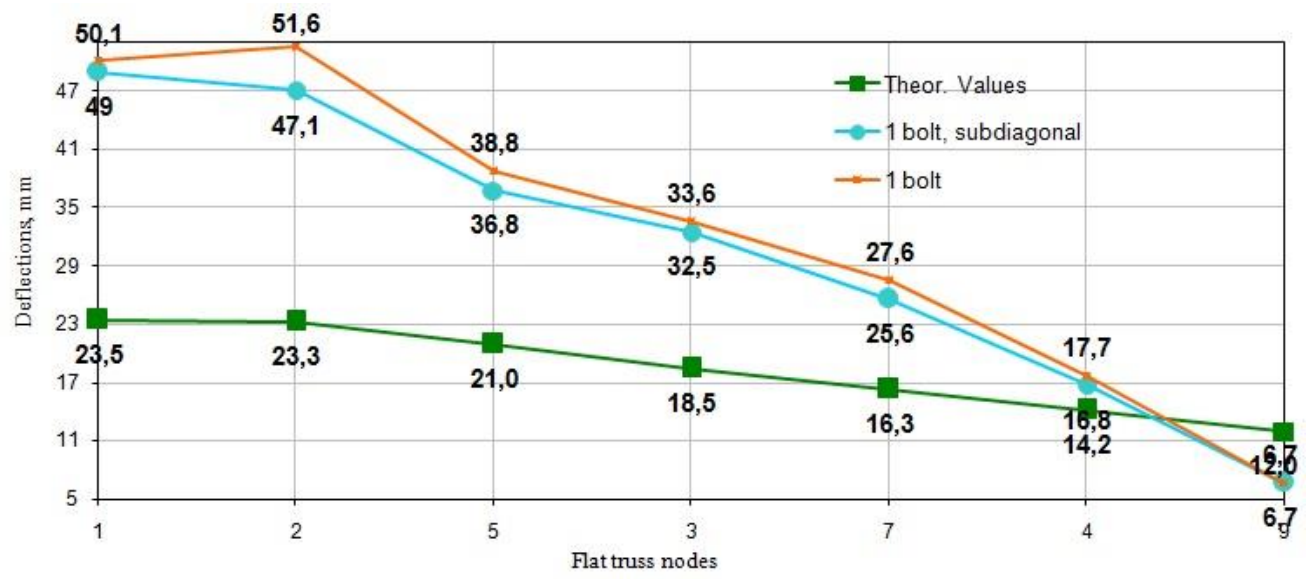

Fig. 14. Nodes displacements with single-bolt braces fastening (lattice L63x5) 


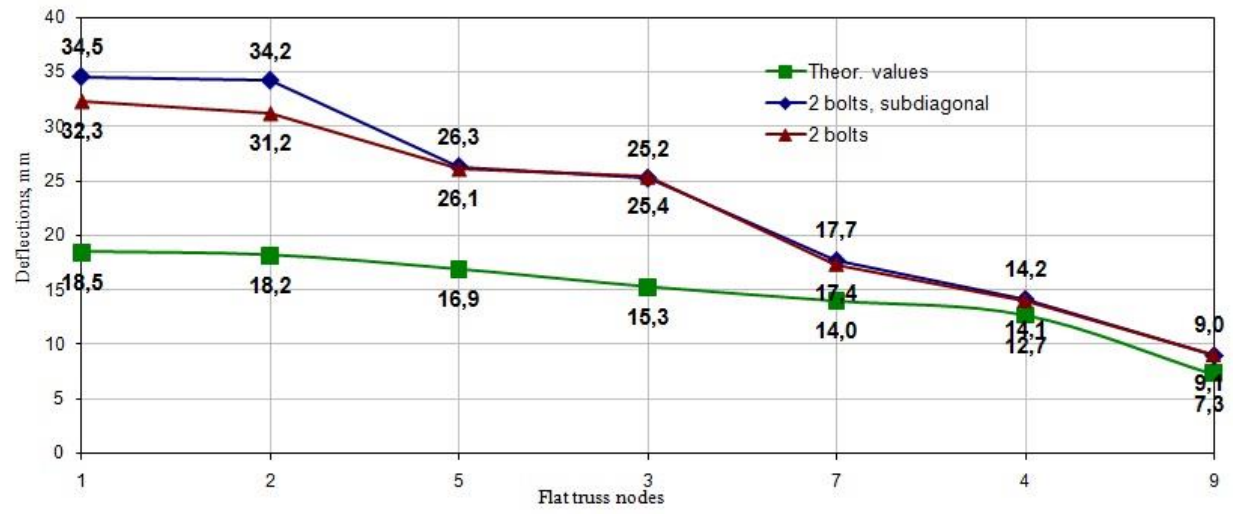

Fig. 15. Nodes displacements with two-bolts braces fastening (lattice L45x4)

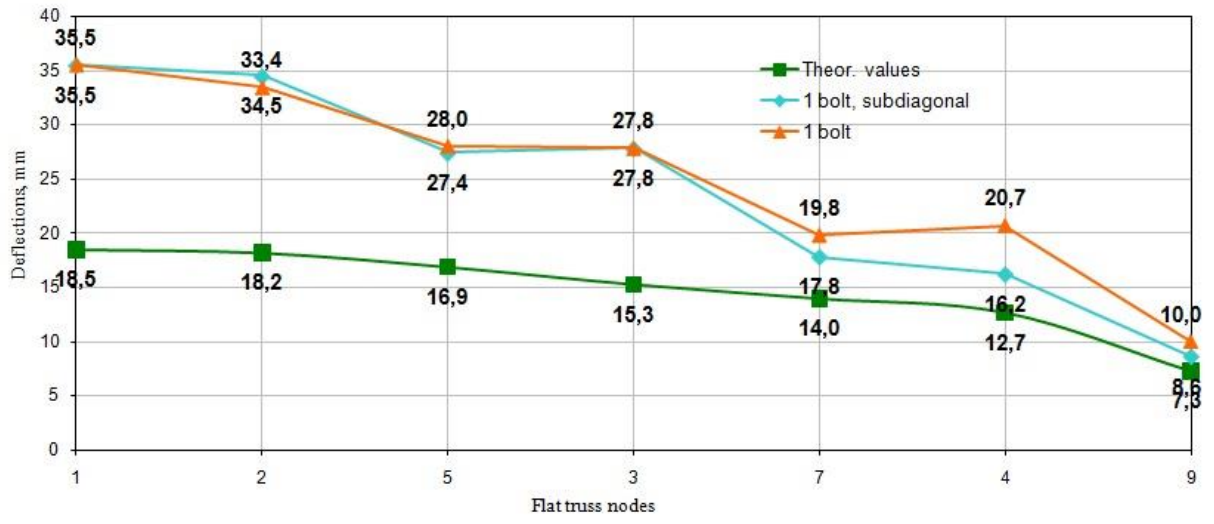

Fig. 16. Nodes displacements with single-bolt braces fastening (lattice L45 4 )

\section{Conclusions}

1. Was approbated the technique of carrying out the static experimental researches of OHPL supports' fragments with a double-bolts and single-bolt fastening of bracing, with and without the subdiagonal lattice.

2. In all cases, the experimental values of displacements are greater than the theoretical values by an average of $36-44 \%$ due to the compliance of bolted joints at the nodes.

3. The deformability of flat trusses with the subdiagonal lattice is less by $1-12 \%$ than similar trusses without it.

4. The deformability of structures with the double-bolts braces fastening to the chord is less by $1-9 \%$ than with the single-bolt fastening.

5. Forces and stresses in the braces of the L63 55 corner with the double-bolts fastening are $11.8 \%$ lower than the theoretical ones, and $8.7 \%$ in the braces of the L $45 \times 4$ corner.

6. Forces and stresses in the braces of the L63 55 corner with the double-bolts fastening are $11.8 \%$ lower than the theoretical ones, and $8.7 \%$ in the braces of the L $45 \times 4$ corner.

7. The experimental values of the stresses in the elements of the testing samples showed that there is a reserve of the load-bearing capacity, so it is necessary to improve the stability technique. 


\section{References}

1. E. V. Shevchenko, Metal structures improvement of the overhead power transmission lines (DNACEA, Makeevka, 1999)

2. IEC 60826 Design criteria of overhead transmission lines (international standard) (IEC, Geneva, 2003)

3. K.P. Krykov, B.P. Novgorodtsev, Structures and mechanical design of power transmission lines (Energia, Leningrad, 1979)

4. B. Yang, Stress, strain, and structural dynamics: an interactive handbook of formulas, solutions, and MATLAB toolboxes (Elsevier Academic Press, Cambrige, 2005)

5. E. V. Gorokhov, S. N. Shapovalov, E.I. Udod, Increase of reliability and durability of electric grid structures (Tekhnika, Kiev, 1997)

6. A.V. Tanasoglo, Mod. Ind. And Civ. Cons. J. 11( 1), 5 (2015)

7. A.V. Tanasoglo, Vest. of DNACEA Build. \& Struc. with N. Mat. And Tech J. 3(113), $50(2015)$

8. A.V. Tanasoglo, Mod. Steel and Timb. Build. Cons. J. 15(3), 233 (2013)

9. E.V. Shevchenko, A.V. Tanasoglo, Vest. of DNACEA. Build. \& Struc. with N. Mat. And Tech J. 3(101), 114 (2013)

10. Ya.V. Nazim, Met. Cons. J. 21(2), 49 (2015)

11. A.V. Perelmuter, V.I. Slivker, Structural design models and their analysis possibility (SCAD, Kiev, 2001)

12. E.V. Shevchenko, A.V. Tanasoglo, V.A. Glukhov, Met. Cons. J. 16 (1), 31 (2010)

13. A.V. Tanasoglo, Met. Cons. J. 18(2), 135 (2012)

14. H. Li, H. Bai, High Prog. in Nat. Sc. J. 16 (9), 899 (2006)

15. Ye. Shevchenko, Ya. Nazim, A. Tanasoglo, I. Garanzha, Proc. Eng. J. 117, 1033 (2015)

16. Rules of electrical installations Chapter 2.5 Overhead power transmission lines with voltage above $1 \mathrm{kV}$ to $750 \mathrm{kV}$ (OEP GRIFE, Kiev, 2006)

17. A. Pustovgar, A. Tanasoglo, I. Garanzha, L. Shilova, A. Adamtsevich, MATEC Web of Conf. J. 86, 19 (2016)

18. A.V. Tanasoglo, Met. Cons. J. 21(3), 107 (2015)

19. A.S.C.E Design of Latticed Steel Transmission Structures (A.S.C.E, New York, 1991)

20. E.V. Gorokhov, V.F. Mushchanov, V.N. Vasylev, Inspection and testing of loadbearing structures of buildings and structures (UMK VO, Kiev, 1991)

21. K.P. Krykov, A.I. Kurnosov, B.P. Novgorodtsev, Design and modeling of metal and reinforced concrete supports for overhead power transmission lines (Energia, Leningrad, 2005)

22. A.G. Sokolov, Supports of power transmission lines: design and construction (Gosstroyizdat, Moscow, 1961)

23. E.V. Gorokhov, V.F. Mushchanov, A.M. Yugov, V.N. Vasylev, Algorithms for the steel structures design (Gosstroyizdat, Moscow, 1999)

24. M.W. Dobbs, L.P. Felton Str. Div. J. 95, 2105 (2009)

25. E.V. Gorokhov, Durability of Steel Structures Under Reconstruction (Brookfield, Rotterdam, 2014).

26. M. Ohsaki, Optimization of Finite Dimensional Structures (CRC Press Taylor \& Francis Group, Tokyo, 2015) 